Revista Eletrônica em Gestão, Educação e Tecnologia Ambiental REGET/UFSM (e-ISSN: 2236-1170).

\title{
PRÁTICAS DE EDUCAÇÃO AMBIENTAL NA GESTÃO DE RECURSOS HÍDRICOS
}

\author{
Larissa Azambuja Alcântara ${ }^{1}$, Maria Clara Araujo Silva ${ }^{1}$, Ronaldo Kanopf de Araújo ${ }^{2}$, \\ Toshio Nishijima ${ }^{3}$ \\ ${ }^{1}$ Aluna do Mestrado em Engenharia Agrícola, UFSM. Email:la engamb@yahoo.com.br \\ ${ }^{1}$ Aluna do Mestrado em Engenharia Agrícola, UFSM. E-mail:mariaclarsi@hotmail.com \\ ${ }^{2}$ Aluno do Mestrado em Engenharia Civil, UFSM, E-mail:ronaldo.kanopf@gmail.com \\ ${ }^{3}$ Prof. Dr.DER/CCR/UFSM, Orientador,E-mail:toshionishijima@gmail.com
}

\section{Resumo}

A falta de sensibilização e conscientização da população e, muitas vezes, dos governantes quanto à preservação dos recursos hídricos tem proporcionado constantes debates sobre as questões do uso racional deste recurso. O enfraquecimento da visão global conduz a diminuição da responsabilidade da sociedade, onde cada cidadão se torna responsável apenas por suas ações, desfazendo-se seus vínculos com a humanidade e, consequentemente despreocupando-se com o bem estar de todos. Para minimizar os danos ambientais há o surgimento de conceitos, práticas e técnicas, que podem proporcionar um convívio equilibrado entre a sociedade e o meio ambiente. Este trabalho visa apresentar conceitos sobre a gestão de águas em comitês de bacia relacionada com práticas de Educação Ambiental. A gestão dos recursos hídricos tem como intuito ajustar as atividades humanas para que não haja a degradação do ecossistema, buscando preservá-lo, por meio de ações conjuntas entre a sociedade e o poder público. No Estado do Rio Grande do Sul foi criada uma proposta de Rede de Educação Ambiental da Bacia do Vacacaí-Mirim, quem tem como base, a comunicação e a educação ambiental. O projeto busca a conscientização e a sensibilização da sociedade, dos governantes e, também dos setores industriais de produção. A participação da comunidade é imprescindível nas práticas da Educação Ambiental. Faz-se necessário expor diferentes valores, percepções e hábitos, para que a comunidade compreenda de forma clara a importância das práticas de educação. Metodologicamente, o projeto da Rede de Educação Ambiental parte da exposição de temas atuais e de interesse comunitário, com enfoque na conscientização dos recursos naturais. Estas informações foram coletadas em escolas que se encontram situadas na Bacia do Vacacaí-Mirim, na cidade de Santa Maria-RS. Dentre as ações propostas podem ser mencionadas campanhas voltadas para o setor industrial, por meio da implementação de medidas para controle de poluição, rede de monitoramento da qualidade da água, contando com o apoio das prefeituras e órgãos estaduais. Também, a promoção de cursos de capacitação em Educação Ambiental para professores; campanhas para a preservação e restauração de ecossistemas, abordando o gerenciamento das águas, o que possibilita uma melhor compreensão do aluno quanto às questões ambientais. Deste modo, com a realização deste projeto, Rede de Educação Ambiental da Bacia do Vacacaí-Mirim, percebe-se uma maior discussão e exposição sobre pontos fundamentais sobre a conscientização do meio ambiente, isto ocorre por meio da inserção de políticas ambientais no meio escolar. As atividades apresentadas ainda são propostas em andamento, atuando no meio escolar e comunitário. E podem ser consideradas como um somatório de ideias que apontam para a conscientização e a sensibilização da sociedade para com as questões ambientais.

Palavras-chave: Água - Educação Ambiental - Vacacaí-Mirim. 


\title{
Revista Eletrônica em Gestão, Educação e Tecnologia Ambiental \\ REGET/UFSM (e-ISSN: 2236-1170).
}

\begin{abstract}
Lack of awareness and awareness of the population and often the rulers and the conservation of water resources has provided constant debates on the issues of rational use this feature. The weakening of global vision leads to decreased societal responsibility, where each citizen becomes solely responsible for their actions, breaking up their ties to humanity and thus unconcerned with the welfare of all. To minimize environmental damage is the emergence of concepts, practices and techniques that can provide a balanced interaction between society and the environment. This work presents concepts of water management in basin committees related to environmental education practices. The management of water resources has the intention to adjust human activities to avoid any degradation of the ecosystem, seeking to preserve it, by means of joint actions between society and government. In the state of Rio Grande do Sul was created a proposal for Environmental Education Network of Basin Vacacaí-Mirim, who is based, communication and environmental education. The project seeks to raise awareness and awareness of society, the rulers and also of the industrial production. Community participation is essential in the practice of Environmental Education. It is necessary to expose different values, perceptions and habits, so that the community understands clearly the importance of education practices. Methodologically, the project's Environmental Education Network part of the exhibition of current topics of community interest, focusing on awareness of natural resources. These data were collected in schools that are located in the Basin Vacacaí-Mirim, in the town of Santa Maria-RS. Among the proposed actions may be mentioned campaigns aimed at the industrial sector, through the implementation of measures for pollution control, network monitoring water quality, with the support of municipalities and state agencies. Also, the promotion of training courses for teachers in environmental education, campaigns for the preservation and restoration of ecosystems, addressing the management of water, which allows a better understanding of student and environmental issues. Thus, with this project, the Environmental Education Network of Basin Vacacaí-Mirim, we find a further discussion and presentation on key points about the awareness of the environment, this occurs through the inclusion of environmental policies in schools. The activities presented proposals are still in progress, working in the school and community. And they can be considered as a sum of ideas that link to and awareness of society in environmental issues.
\end{abstract}

Keywords: Water - Environmental Education - Vacacaí-Mirim.

\section{Introdução}

A água é um recurso natural essencial para a sadia qualidade de vida, visto que é um bem insubstituível para o desenvolvimento de todos os seres vivos.

A falta de sensibilização e conscientização da população e, muitas vezes, dos governantes

quanto à preservação dos recursos hídricos tem proporcionado constantes debates sobre as questões do uso racional deste recurso, ocasionando conflitos sócio-ambientais. De acordo com Morin (2000) o enfraquecimento da visão global conduz a diminuição da responsabilidade da sociedade, onde cada cidadão se torna responsável apenas por suas ações, desfazendo-se seus vínculos com a humanidade e, consequentemente despreocupar-se com o bem estar de todos. Com isso, cada cidadão não deve apenas pensar em si, visto que este está inserido na sociedade e, esta necessita de ações em benefício de todos, bem como do ecossistema. Ainda, segundo o autor, o aumento da problemática ambiental resulta da expansão da tecnologia e do crescimento 


\section{Revista Eletrônica em Gestão, Educação e Tecnologia Ambiental REGET/UFSM (e-ISSN: 2236-1170).}

populacional, pois atualmente percebemos que, quanto mais um determinado local se desenvolve, mais degradação ocorre.

Para minimizar os danos ambientais há o surgimento de conceitos, práticas e técnicas, que podem proporcionar um convívio equilibrado entre a sociedade e o meio ambiente, buscando a preservação dos recursos naturais. Uma das soluções seria a gestão dos recursos hídricos, enfoque deste trabalho. A gestão dos recursos hídricos tem como intuito ajustar as atividades humanas para que não haja a degradação do ecossistema, buscando preservá-lo, por meio de ações conjuntas entre a sociedade e o poder público (NUNES et al., 2011). Vale ressaltar que estas práticas de gestão serão viáveis e eficientes se tivermos como base, clara e objetiva, a educação ambiental, visto que, o ponto de partida encontra-se na conscientização da população e de seus governantes para manter o meio natural em equilíbrio.

No que se refere à gestão dos recursos hídricos, a participação da sociedade para a manutenção dos corpos d'água é fundamental e, é garantida por meio da representação de usuários e das organizações não governamentais nos comitês de bacia, que debatem e expõe questões referentes à gestão das águas.

Deste modo, este trabalho justifica-se por expor conceitualmente pontos da gestão de recursos hídricos, com enfoque na Educação Ambiental aplicada em comitês de bacias.

\section{Objetivo geral}

Este trabalho visa apresentar conceitos sobre a gestão de águas em comitês de bacia relacionada com práticas de Educação Ambiental.

\subsection{Objetivos específicos}

- Expor a importância da Gestão de Recursos Hídricos através de uma abordagem conceitual;

- Apresentar práticas utilizadas na Rede de Educação Ambiental da Bacia do Vacacaí-Mirim na região de Santa Maria/RS.

\section{Referencial teórico}

\subsection{A bacia do Vacacaí-Mirim}

Abaixo segue um breve relato sobre alguns dados da área da bacia do Vacacaí-Mirim, com suas características e localização dentro do Estado do Rio Grande do Sul. A localização dos rios Vacacaí e Vacacaí-Mirim, estão diretamente ligados às bacias hidrográficas, fazendo parte da Depressão Central do Rio Grande do Sul. Suas coordenadas geográficas são de $29^{\circ} 35^{\prime}$ a $30^{\circ} 45^{\prime}$ de latitude sul; e $53^{\circ} 04^{\prime}$ a $54^{\circ} 34^{\prime}$ de longitude oeste. Totaliza uma área de $11.085,77 \mathrm{~km}^{2}$, abrangendo uma população de aproximadamente 407.533 habitantes (MARCHESAN, 2009).

O Rio Vacacaí-Mirim tem suas nascentes na Serra do Pinhal e seu curso se desenvolve até chegar a cidade de Santa Maria. A área contribuinte ao reservatório apresenta cerca de $29 \mathrm{~km}^{2}$, sua vegetação é caracterizada como mata nativa e, tem-se também cultivos anuais permanentes, pecuária e balneários (MARINS, 2004). O rio principal tem área de drenagem de aproximadamente $18,4 \mathrm{~km}^{2}$ e comprimento de $7 \mathrm{~km}$ (BRANCO et al, 1998).

A microbacia está situada entre as coordenadas geográficas 53 $46^{\prime} 30^{\prime \prime}$ a $53^{\circ} 49^{\prime} 29^{\prime \prime}$ de

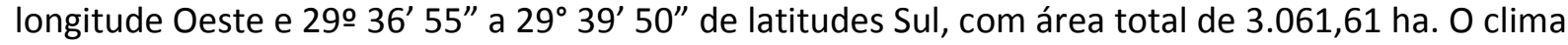
da região é classificado em sub-tropical "Cfa", com temperatura média anual de 19,3ㄷ e, a precipitação média anual é superior a 1.500 mm (GRACIOLI, 2008). 


\section{Revista Eletrônica em Gestão, Educação e Tecnologia Ambiental REGET/UFSM (e-ISSN: 2236-1170).}

Deste modo, o Vacacaí-Mirim faz parte de uma rede de drenagem muito importante no Estado do Rio Grande do Sul, necessário para o desenvolvimento ecológico e urbano.

\subsection{Rede de Educação Ambiental na Bacia Hidrográfica do rio Vacacaí-Mirim}

O aumento do consumo de água, bem como a possível escassez deste recurso faz com que sejam necessários o desenvolvimento de estratégias, técnicas e políticas públicas com visão voltada para a sustentabilidade para pôr em prática sistemas de gestão a fim de preservar o meio hídrico. Uma forma de se tornar viável a preservação deste recurso é o desenvolvimento dos comitês de bacias hidrográficas. Os Comitês de Bacias Hidrográficas podem ser conceituados de uma forma simples, como sendo um órgão colegiado com o objetivo de discutir questões relacionadas à gestão dos recursos hídricos. A Lei das Águas coloca uma série de competências aos comitês de bacias, como:

I - promover o debate das questões relacionadas a recursos hídricos e articular a atuação das entidades intervenientes;

II - arbitrar, em primeira instância administrativa, os conflitos relacionados aos recursos hídricos;

III - aprovar o Plano de Recursos Hídricos da bacia;

IV - acompanhar a execução do Plano de Recursos Hídricos da bacia e sugerir as providências necessárias ao cumprimento de suas metas.

$\mathrm{VI}$ - estabelecer os mecanismos de cobrança pelo uso de recursos hídricos e sugerir os valores a serem cobrados;

IX - estabelecer critérios e promover o rateio de custo das obras de uso múltiplo, de interesse comum ou coletivo. (ART. 38, LEI 9.433/97).

Diante das atividades que cabem aos comitês de bacias, pode-se perceber sua importância para a construção de novos paradigmas em benefício da gestão dos recursos hídricos, aliados a princípios da Educação Ambiental.

$\mathrm{O}$ assunto de Educação Ambiental relatado a partir desde ponto foi desenvolvido na Bacia Hidrográfica do Vacacaí-Mirim, onde esta é composta por 16 municípios.

No Estado do Rio Grande do Sul foi criada uma proposta de Rede de Educação Ambiental da Bacia do Vacacaí-Mirim, definida em termos conceituais pelas Leis Federal № 9.433/97 e Estadual № 10.350/94, que instituíram o Sistema Nacional e Estadual de Recursos Hídricos, respectivamente, abordando a descentralização e a participação social na tomada de decisões sobre as águas de domínio da União e do Estado do RS.

A proposta tem como base a comunicação e a educação ambiental, visando a articulação e organização dos núcleos municipais e a implementação de apoio a Rede de Educação Ambiental (REA) nos 16 municípios integrantes da bacia hidrográfica do Vacacaí e Vacacaí-Mirim. A proposta busca ações conjuntas entre a sociedade e o poder público, assim tem-se as especificações:

reforçar a construção política da relação das Prefeituras Municipais em torno do Comitê e da participação efetiva das mesmas na implementação do processo de gestão dos recursos hídricos; organização de equipe dirigida à formação e capacitação de agentes ambientais e de recursos hídricos oriundos da comunidade, em conjunto com cada um dos municípios; campanha de mobilização social envolvendo a comunidade em geral e os escolares nas atividades de gestão ambiental e de recursos hídricos; distribuição de materiais com o objetivo de educação ambiental (DOTTO, 2009). 


\section{Revista Eletrônica em Gestão, Educação e Tecnologia Ambiental REGET/UFSM (e-ISSN: 2236-1170).}

O Projeto Rede de Educação Ambiental na Bacia Hidrográfica dos Rios Vacacaí e VacacaíMirim (REAVacacaí) ainda se encontra em construção e, é executado pela Universidade Federal de Santa Maria - UFSM. Busca a conscientização e a sensibilização da sociedade, dos governantes e, também dos setores industriais de produção. Esta visão nos permite notar que esta proposta é de fundamental importância para a manutenção e preservação ambiental, apresentando a educação ambiental como ponto de partida, seguida de sistemas de gerenciamento, onde estes têm como finalidade a minimização dos impactos negativos sobre os recursos naturais.

A Rede de Educação Ambiental dos rios Vacacaí e Vacacaí-Mirim foi implantada para desenvolver uma educação ambiental de modo formal e não formal (DOTTO, 2009). Desta maneira, pode-se dizer que este projeto fundamenta-se numa ação integradora, com fortalecimento no conhecimento dos conflitos sócio-ambientais, na conscientização, no comprometimento e no poder participativo da sociedade agindo paralelamente com a atuação dos gestores públicos.

Assim, a Educação Ambiental é um instrumento de gestão e, atua de forma significativa na busca pelo desenvolvimento sustentável.

\subsection{Importância da Educação Ambiental em bacias hidrográficas}

A aplicação de projetos de Educação Ambiental, utilizando a bacia hidrográfica como unidade de ensino, faz com que acrescente conhecimentos sobre a percepção e a sensibilização ambiental.

Segundo Tundisi \& Schiel (2002), a bacia hidrográfica como unidade de educação ambiental relaciona-se como um laboratório experimental, buscando a integração de conhecimentos de diferentes áreas de atuação. Com isso, a bacia hidrográfica apode atuar como unidade de ensino, com planejamento e gerenciamento tornando-se indispensável para o desenvolvimento sustentável, bem com, para a conscientização da sociedade e das comunidades na qual estão inseridas, pois abrange diferentes áreas de conhecimentos.

Por meio da participação da sociedade é possível ampliar a relação educação-ambiente, onde estamos inseridos e de que somos parte, buscando alternativas para os problemas socioambientais (LOUREIRO, 2006).

Desta maneira, a participação da comunidade é imprescindível nas práticas da Educação Ambiental. Faz-se necessário expor diferentes valores, percepções e hábitos, para que a comunidade compreenda de forma clara e objetiva a importância das práticas de educação, buscando uma visão sócio-educativa e política.

Segundo Trevisol (2010) diante da complexidade ambiental, o conhecimento é extremamente importante na construção de novos valores, novas autonomias, tanto no sentido de instigar as atitudes, bem como, de acentuar a compreensão das relações entre a humanidade e a qualidade ambiental.

Assim, por meio da compreensão, da conscientização e da sensibilidade da sociedade, juntamente com a inserção da Educação Ambiental em redes de Bacia Hidrográfica, formam-se interrelações, na qual primam por uma nova visão de sustentabilidade, mantendo o equilíbrio do meio ambiente, a sadia qualidade de vida e do ecossistema. 


\section{Revista Eletrônica em Gestão, Educação e Tecnologia Ambiental \\ REGET/UFSM (e-ISSN: 2236-1170).}

\section{Metodologia}

A Educação Ambiental deve ser abordada de forma interdisciplinar, atuando em diferentes níveis de ensino, possibilitando o desenvolvimento de atividades que remetam a preservação ambiental.

Metodologicamente, o projeto da Rede de Educação Ambiental parte da exposição de temas atuais e de interesse comunitário, com enfoque na conscientização dos recursos naturais.

\subsection{Coleta de informações}

Primeiramente foi realizada a coleta de informações sobre o que a sociedade participativa entende por Educação Ambiental, ou seja, que idéia elas fazem deste conceito. Estas informações foram coletadas em escolas que se encontram situadas na Bacia do Vacacaí-Mirim, na cidade de Santa Maria-RS, abrangendo: Ensino Infantil: 136; Ensino Fundamental: 115; Ensino Médio: 30.

Estes dados são referentes ao ano 2003, os quais fornecem o número de escolas da região da Bacia do Vacacaí e Vacacaí-Mirim - estabelecimento estadual, federal, municipal e privado - e disponível em: $<<$ http://www.portalmunicipal.org.br $>>$.

\subsection{Ações desenvolvidas em âmbito escolar}

Algumas atividades foram desenvolvidas nos setores de cada escola, proporcionando a interatividade entre as diversas disciplinas do meio pedagógico, fornecendo um maior conhecimento sobre as questões ambientais. Dentre as atividades pode-se citar:

- Exposição conceitual sobre questões de educação ambiental e conscientização;

- Apontamento de efeitos negativos no meio ambiente bem como, buscar alternativas para diminuir os danos ambientais;

- Palestras que envolvam conceitos sobre reduzir, reutilizar e reciclar (Política dos 3 R's);

- Interação no âmbito escolar entre alunos, professores e diretores com a criação de programas que visem à conscientização ambiental;

- Desenvolvimento de atividades para alunos, por meio da mídia informativa (reportagens, documentários, filmes com temática ambiental, entre outras);

- Atividades artísticas com a reutilização de materiais descartados;

- Elaboração de cartilhas e murais ecológicos;

- Utilização de materiais informativos referentes às práticas de conservação do meio ambiente.

Devem-se destacar o Dia 22 de Março, o Dia Mundial da Água e, que vem a ser também o Dia Nacional da Água no Brasil, com o desenvolvimento de atividades, como cursos, palestras de conscientização e a exposição da dinâmica do funcionamento do ciclo hidrológico, vital para a existência de vida no mundo.

Este processo de sensibilização, de certa forma, torna-se como uma iniciativa ao desenvolvimento sustentável, pois a medida este que ultrapassa o ambiente escolar promove uma melhor qualidade de vida para o bairro na qual a escola está inserida, e onde estão sendo exercidas as práticas de Educação Ambiental. 


\section{Revista Eletrônica em Gestão, Educação e Tecnologia Ambiental REGET/UFSM (e-ISSN: 2236-1170).}

\subsection{Ações da Rede de Educação Ambiental do Vacacaí-Mirim}

As ações propostas pela REA são de grande importância para manter o equilíbrio do meio natural. Podem ser mencionadas campanhas voltadas para o setor industrial, por meio da implementação de medidas para controle de poluição, contando com o apoio das prefeituras e órgãos estaduais para minimizar problemas relacionados ao destino dos resíduos sólidos.

Apresenta também a implantação de uma rede de monitoramento da qualidade da água, do qual fazem parte do projeto, a Companhia Riograndense de Saneamento (CORSAN), o Departamento Municipal de Água e Esgotos de Santa Maria.

Promove cursos de capacitação em Educação Ambiental para professores; campanhas para a preservação e restauração de ecossistemas; ações de incentivo à educação ambiental, ao controle da poluição industrial e à solução de problemas de saneamento básico nas áreas de resíduos sólidos, esgotamento sanitário e abastecimento público de água, entre outras. Aborda o gerenciamento das águas, o que possibilita a compreensão do aluno quanto às questões sobre uma bacia hidrográfica e sua importância, visualizando a hidrografia do Rio Grande do Sul, a rede hidrográfica de Santa Maria com os rios Cadena, e do Vacacaí-Mirim, integrante da Bacia Hidrográfica dos Rios Vacacaí e Vacacaí-Mirim, por meio de palestras e aulas expositivas.

\section{Resultados e Discussão}

Com a realização deste projeto, Rede de Educação Ambiental da Bacia do Vacacaí-Mirim, percebe-se uma maior discussão e exposição sobre pontos fundamentais sobre a conscientização do meio ambiente, isto ocorre por meio da inserção de políticas ambientais nas escolas de Santa Maria e de outros municípios próximos. Essa conscientização envolve dois aspectos fundamentais: a compreensão do indivíduo de que ele é parte integrante do ambiente e, que suas ações podem alterar o meio em que vive; e um segundo aspecto, ele atua como participante da sociedade, expondo suas ideias e compartilhando de direitos e deveres.

No âmbito escolar, o desenvolvimento de projetos escolares integrados, com a participação de professores, funcionários públicos, gestores, bem como a sociedade de um modo geral, proporciona o surgimento de atividades e alternativas, expondo a problemática ambiental, buscando-se soluções para minimizar os impactos provocados no meio ecológico.

Desta forma, o trabalho da Rede de Educação Ambiental da Bacia do Vacacaí-Mirim vem contribuindo de maneira significativa para os alunos de todos os níveis de ensino e, professores atuantes em diferentes áreas pedagógicas, potencializando ações de Educação Ambiental no âmbito escolar.

\section{Conclusão}

As atividades apresentadas por meio do Projeto de Rede de Educação Ambiental pela Bacia do Vacacaí-Mirim ainda são propostas em andamento, atuando presentemente no meio escolar e comunitário. E podem ser consideradas como um somatório de ideias que apontam para a conscientização e a sensibilização da sociedade para com as questões ambientais.

Com isso, a Educação Ambiental fazem com que possamos rever hábitos, valores e atitudes, inserindo as práticas individuais em benefício da coletividade, proporcionando uma melhor qualidade de vida. Assim, observa-se que a Educação Ambiental e a conservação dos recursos hídricos são meios importantes para que, em um futuro próximo, não venhamos a sofrer as conseqüências da falta de atitudes conscientes e despreocupadas com o presente. 


\section{Revista Eletrônica em Gestão, Educação e Tecnologia Ambiental \\ REGET/UFSM (e-ISSN: 2236-1170).}

\section{Referências bibliográficas}

BRANCO, N.; PAIVA, J. B. D. et al. Produção de Sedimentos na BaciaHidrográfica do Arroio Vacacaí-Mirim Avaliação Preliminar. In: XVII CONGRESSO NACIONAL DEL AGUA E II SIMPOSIO DE RECURSOS HÍDRICOS DEL CONO SUR., 1998, Santa Fé. Santa Fé: ABRH Digital, 1998. V.3. p.444-451.

BRASIL. Lei 9.433/97 - Política Nacional de Recursos Hídricos. Disponível em: <http://www.planalto.gov.br/ccivil 03/LEIS/I9433.htm> Acesso em: 31 jul de 2011.

DOTTO, Carlos R. D. Histórico da Construção da Proposta da "REA Vacacaí" - Período de 2000 à 2009 REA - Rede de Educação Ambiental da Bacia Hidrográfica dos rios Vacacaí e Vacacaí-Mirim. Universidade Federal de Santa Maria, Centro de Ciências Rurais. Santa Maria/RS, 2009.

GRACIOLI, C. R.; ROCHA, J.S.M. Impactos ambientais na microbacia hidrográfica do rio Vacacaí-Mirim em Santa Maria, RS. Ambiência - Revista do Setor de Ciências Agrárias e Ambientais V. 4 N. 2 Maio/Ago. 2008.

LOUREIRO, C. F. B. Problematizando conceitos: contribuições à práxis em educação ambiental. In: Pensamento complexo, dialética e educação ambiental. São Paulo: Cortez, 2006.

MARCHESAN, E. et al.; Qualidade de água dos rios Vacacaí e Vacacaí-Mirim no Estado do Rio Grande do Sul, Brasil. Cienc. Rural vol.39 no.7 Santa Maria Oct. 2009 Epub Aug 14, 2009.

MARINS, A.P. Simulação hidrológica do Reservatório do Vacacaí-Mirim/Santa Maria-RS utilizando o Sistema IPHS1. Dissertação de Mestrado, 2004.

MORIN, Edgar- Os sete saberes necessários à educação do futuro / Edgar Morin ; tradução de Catarina Eleonora F. da Silva e Jeanne Sawaya ; revisão técnica de Edgard de Assis Carvalho. - 2. ed. - São Paulo : Cortez ; Brasília, DF : UNESCO, 2000.

NUNES, Teresa C. de O. et al. A Educação Ambiental na preservação dos corpos hídricos no Estado do Rio de Janeiro. Disponível em: <http://www.revistaea.org/artigo.php?idartigo=1008\&class=02> Acesso em: 31 jul de 2011.

TREVISOL, J.V. et al.; A Educação Ambiental em Bacias Hidrográficas: uma experiência nas escolas públicas do Rio do Peixe (SC). Rev. eletrônica Mestr. Educ. Ambient. ISSN 1517-1256, v. especial, 2010.

TUNDISI, J. G.; SCHIEL, D. A bacia hidrográfica como laboratório experimental para o ensino de Ciências, Geografia e Educação Ambiental, 2002. 